
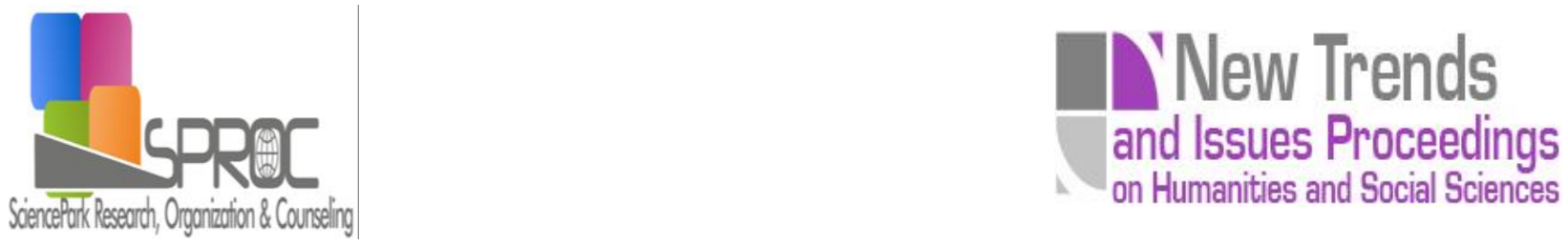

\title{
The impact of physical exercises over the intimate life of the young generation (The Rorschach ink blot test)
}

Elena Lupu*

Suggested Citation:

New Trends and Issues Proceedings on Humanities and Social Sciences.

Abstract 
1. Introduction

\section{Hypothesis}

\section{Methods}

$\boldsymbol{R}$

4. Research content 
Motion" [M], "Color" [Col], "Form" connected to the type of emotion of the subject [Fo] or "Depth" [Dep]." 
assignation of identities,

The evaluation!

The score obtained can be between: 0 points and 54 points, and the 54 points represent the maximum score. the evaluation scales in detail:

- The OV scale: overview

- The Bg scale: background

- The Det scale: details (

- The Ref scale: zero interpretations

The total score is added and is calculated as following:

has two structures:

Stucture I - contains

Stucture II - contains

Important.

Group I - Girls (G) -

$66.66 \%$

a. students capable of physical effort

$25.60 \%$

b. students capable of physical effort, 
c. students who are not capable of physical effort,

Group II - Boys (B) - in number of 41,

$33.34 \%$ had the following structure, as it may be observed from the data recorded in Tables number 3, 4, and Graph number 2:

students capable of physical effort

students capable of physical effort,

Table 1. Registered indicators for the impact of physical exercises over the intimate life (representative aspects: somatic indices - $(\mathrm{H}, \mathrm{Kg})$; exam. average; practiced sports; connection with the P.C. for - 82 - girls (G)

Table 2. Registered indicators for "The Rorschach ink blot test" and its evaluation scales (The Ov scale overview scale; the Bg scale - background; the Det scale - details) for - 82 - girls (G) 


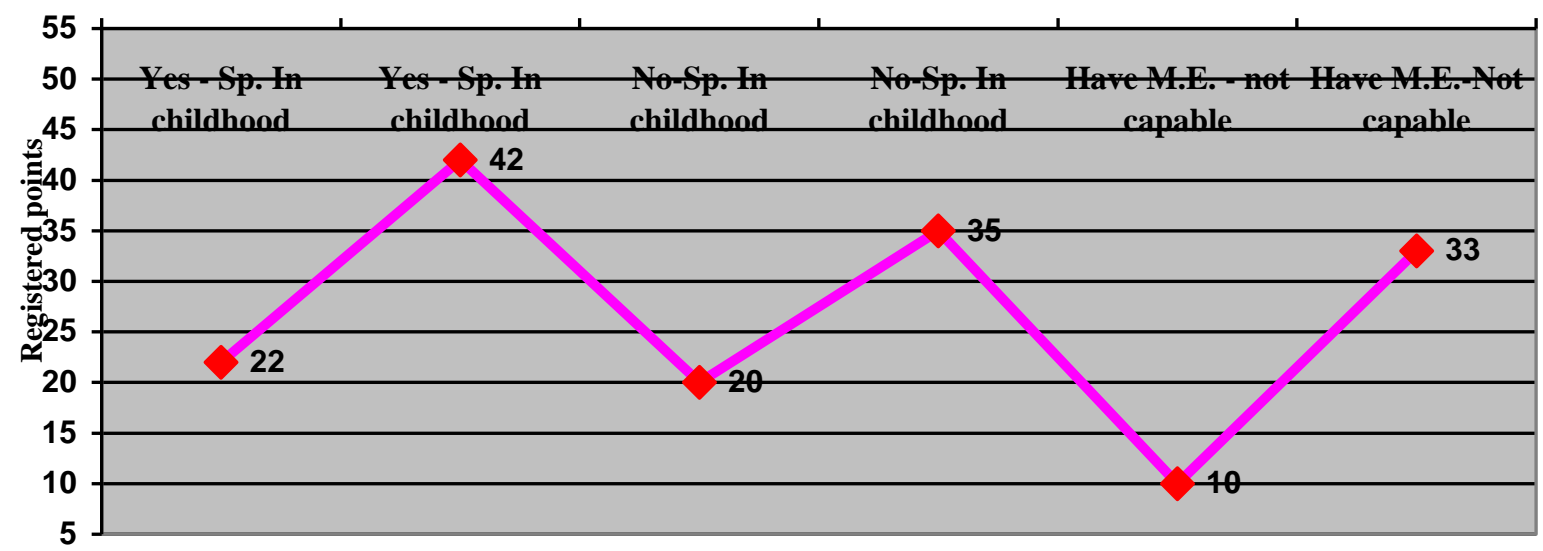

raph 1. Graphical interpretation regarding the points registered at the addition of the evaluation scale (The Ov scale + the Bg scale + the Det scale) for -82 - girls (G)

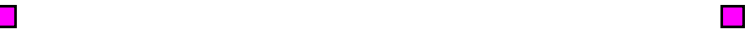

$\bullet$

-

$\square$

\section{Students who practiced}

signal us that female students are not strong enough when facing problems, but can be situated "on average coordinates", with the possibility of evolving towards knowledge through training; 
Students who did not practice any type of sports game who practiced

of subjects who are not strong enough when facing problems, who fit perfectly in the category of executors, but still have the possibility of evolving towards knowledge through training, as a consequence, those who did not practice sports during childhood, but are not sedentary people, and practice physical activities at school, have a similar type to students from 
Table 3. Registered indicators for the impact of physical exercises over the intimate life (representative aspects: somatic indices - $(\mathrm{H}, \mathrm{Kg})$; exam. average; practiced sports; connection with the P.C. for - $41-$ boys (B)

Table 4. Registered indicators for "The Rorschach ink blot test" and its evaluation scales (The Ov scale - overview scale; the Bg scale - background; the Det scale - details) for - 41 - boys (B) 


\section{References}

Physical exercises for an active life - Motric activities for leisure time

Theory of motric activities.

The methodology of research for body activities. Physical Exercise. Sport. Fitness,

The self and defense mechanisms

Disciplined mind

Fundaments of psychology I, II.

Personality tests. Profiles and types of personality. Complete tests and exercises. Analyses and evaluations. 400 Questions

Outdoor recreation in America 